\title{
THE DEVELOPMENT OF SOLAR ENERGY-GAS COUPLING SYSTEM (SCADA) IN BUILDINGS
}

\author{
Xu Hui ${ }^{1}$, Cai Yingling ${ }^{2}$, Yang Huizhen ${ }^{3}$ \\ ${ }^{1}$ College of Mechanical Engineering, Shanghai University of Engineering Science, Shanghai201620, China \\ ${ }^{2}$ College of Mechanical Engineering, Shanghai University of Engineering Science, Shanghai201620, China \\ ${ }^{3}$ College of Mechanical Engineering, Shanghai University of Engineering Science, Shanghai201620, China
}

\begin{abstract}
The system mainly use wall-mounted gas boiler and give priority in use of solar energy in order to maximize the utilization of solar resources. The excess heat will be added to domestic water when the heat for floor radiant heating is enough. The PLC of Siemens is set as slave computer in the monitoring system and it is used to collect thermal parameters such as temperature, flow rate, etc. by temperature sensors, pressure sensors and flow rate sensors. WinCC is set as the host computer to monitor the operating conditions of the entire system. Real-time tracing, monitoring and alarming function can be achieved based on the SQL database, which has realized archive management of the date. The system has been debugged after the whole experiment platform is completed, and the running state of the system shows that this system has high reliability and good stability.
\end{abstract}

Keywords: Solar Energy, Gas, PLC, WinCC, Database

\section{INTRODUCTION}

Development of renewal energy and clean energy is becoming an inevitable tendency of energy structure transform, which is in conformity with China's current situation. As one of the cleanest energy, solar energy is also an inexhaustible source. However, the characteristics of solar energy such as intermittent, instability, low energy flux density, etc. lead to instability of the solar thermal system. Wall-mounted gas boiler can very convenient and quickly to provide hot water for daily life and heating to buildings, but it's not only benefit to realize the energy conservation and environment protection goal but also consume lots of gas by using wall-mounted gas boiler to heat the building alone. Coupling the two kinds of clean energy (solar energy and gas) can learn from each other. And this coupling not only fully utilized the solar energy but also alleviate the shortage of the non-renewable gas. Obviously, this method has great potential for energy saving. The temperature of the fluid is a critical parameter on the study of the solar energy-gas coupling system and provides basis for mode switching of the entire system. The measurement of temperature has important significance for solar energy-gas coupling system's control and operation. Therefore, control method and application of solar energy-gas coupling system will be discussed in this paper ${ }^{[1-3]}$.

\section{OPTIMIZATION DESIGN OF SOLAR ENERGY-GAS COUPLING SYSTEM}

Solar energy-gas coupling system includes four main parts. It is solar-collector system, auxiliary system of gas, terminal system of users, monitoring system, respectively. The solarcollector system is mainly used to collect solar energy and ensure the system operate safely and normally. Auxiliary system of gas is mainly used to make up the shortage of solar energy when the weather is bad or large energy is needed, and it can supply heating quickly. Terminal system of users is mainly used to regulate and control the priority level or complementary of hot water storage tank and gas water heater. Monitoring system is mainly used to ensure the whole system can be controlled and measured, and then regulate and control the flow direction and flow rate of hot water according to the needs of users. The hardware of the system is mainly composed by plate solar collector, hot water storage tank, wall-mounted gas boiler, heating fan coil unit, three-way valve, pumps, etc ${ }^{[4-5]}$.

Based on the previous research and standing on the "shoulder" of the technology of solar energy storage and gas application has becoming more and more mature, the solar energy-gas coupling system was put forward in this article. The system is different from the single traditional heating mode or merely simple superposition of two systems. Based on the data feedback of energy consumption monitoring system, the water in the hot water storage tank will be heated according to actual demands of users, based on the local weather condition and take full advantage of the extra heat of floor radiant heating which provided by solar energy and gas, the efficiency of the entire system will be improved by this way. The system has good practicability and requires a small initial investment. Traditional heating system has some shortages such as large area occupied, large amount of resources consumption, etc. The most important defect in ground source heat pump (GSHP) is the unbalance load of summer and winter which lead to the imbalance of ground temperature-field. According to the coupling system not only these problems will be solved, but also the usage of resource will be improved. The system schematic is shown in figure 1. 


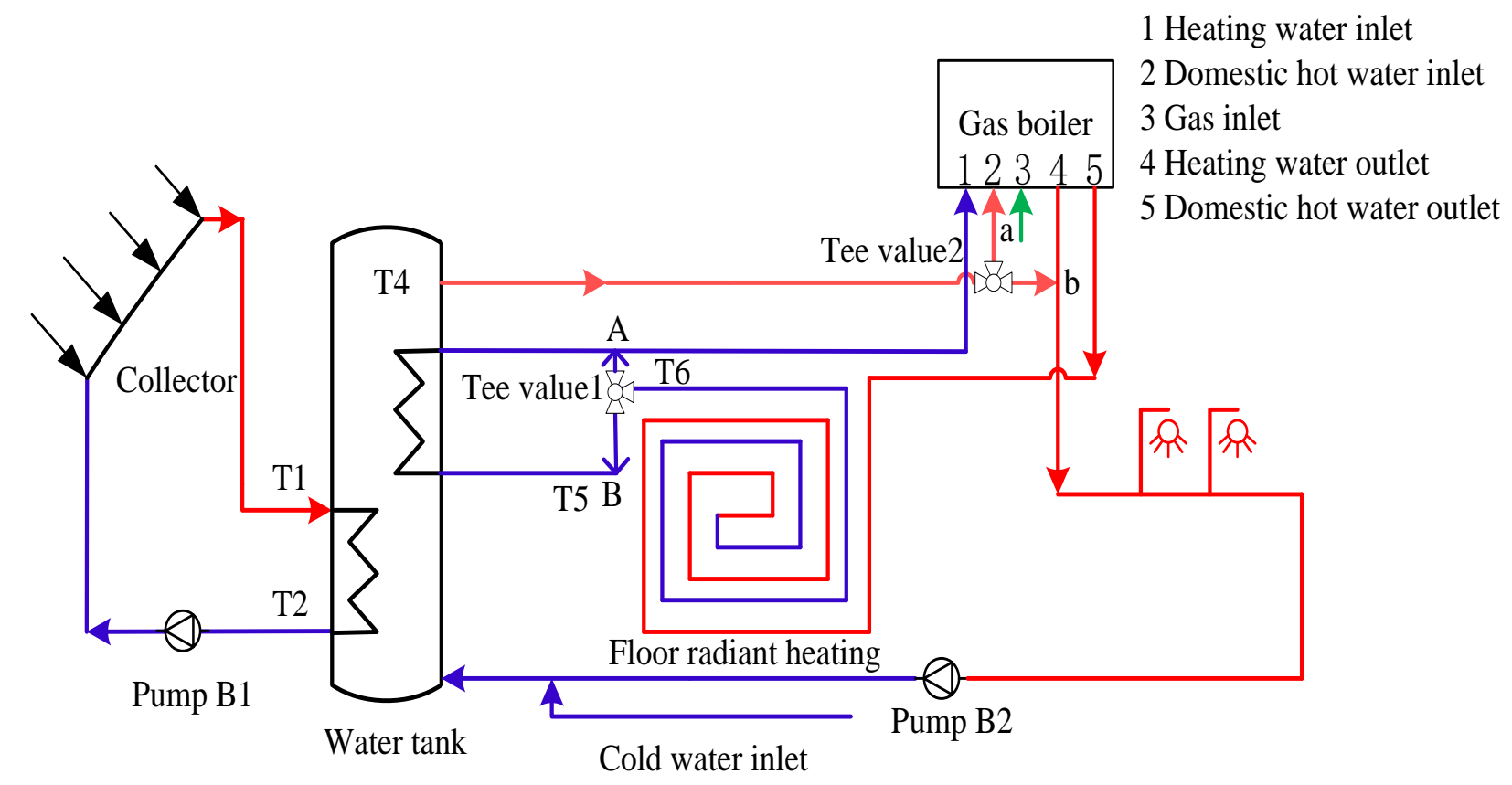

Fig -1: Schematic diagram of solar energy-gas coupling system

\section{DESIGN OF MONITORING SYSTEM}

\subsection{Regulations of the Solar Energy-gas Coupling}

\section{System Control}

\subsubsection{The Solar-Collector System}

The water in the storage tank will be heated by hot water in the solar-collector system. Temperature difference control method is adopted in this circulation system. When the temperature of heat media difference between the inlet temperature named $\mathrm{T} 1$ and outlet temperature named $\mathrm{T} 2$ is larger than $8^{\circ} \mathrm{C}$ (it can be set at the range of $5-8^{\circ} \mathrm{Cby}$ the users), the circulation pump (B1) of solar-collector will be started after 3 minutes to accelerate the process of heat transfer in order to meet the demands of users. When the temperature difference is less than $3^{\circ} \mathrm{C}$ delay 3 minutes and then turn off circulation pump (B1) until the temperature difference is in steady state. Only in this control method, the frequent start and stop of the B1 pump caused by surge temperature can be avoided. It's unnecessary to run the solar-collector system when the day is a rainy day or it's a foggy day. That is because the solar energy in these weather of less open value for the system in this case. The solarcollector system also will be turned off to avoid the irreversible damage to the storage tank caused by excessive temperature and influence the performance of the system in late stage if the temperature of $\mathrm{T} 4$ is larger than $75^{\circ} \mathrm{C}$ The control flow chart is presented in figure 2.

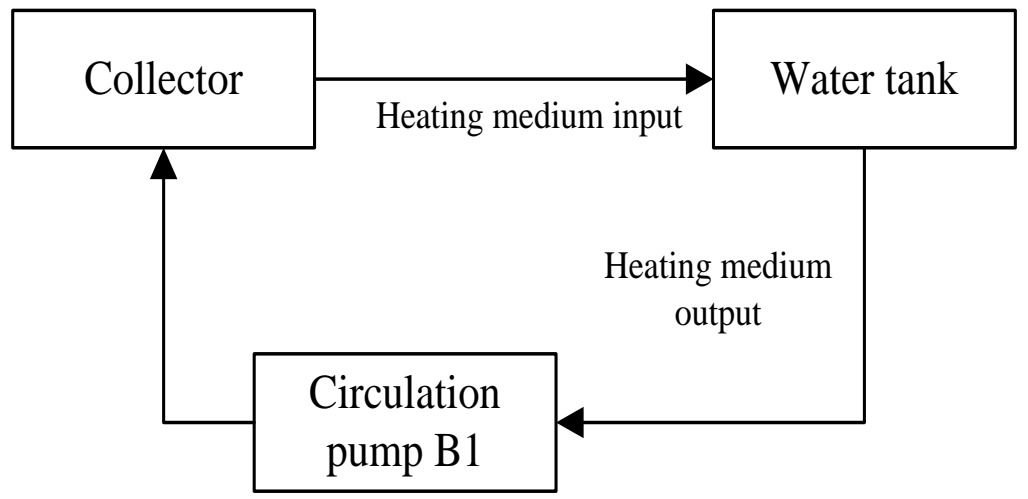

Fig -2: The flow chart of solar thermal system

\subsubsection{The System of Domestic Hot Water}

The hot water provided to the users will be offered by the solar-collector system or the wall-mounted gas boiler system. The hot water and cold water in the storage tank will be stratified due to the density difference caused by different temperature, and the hot water will in the upper of the storage tank. The tee valve will be turned on in the direction of (b) and provides domestic hot water to users directly if 
the temperature of $\mathrm{T} 4$ is larger than $60^{\circ} \mathrm{C}$ However, if the temperature of $\mathrm{T} 4$ is less than $60^{\circ} \mathrm{C}$, the tee valve will be turned on in the direction of (a) and the water in the storage tank will be delivered to the wall-mounted gas boiler and be heated, then it will be provided to users as domestic hot water. There is a supply valve at the bottom of the storage tank to replenish the water which has been consumed. The control flow chart is presented in figure 3 .

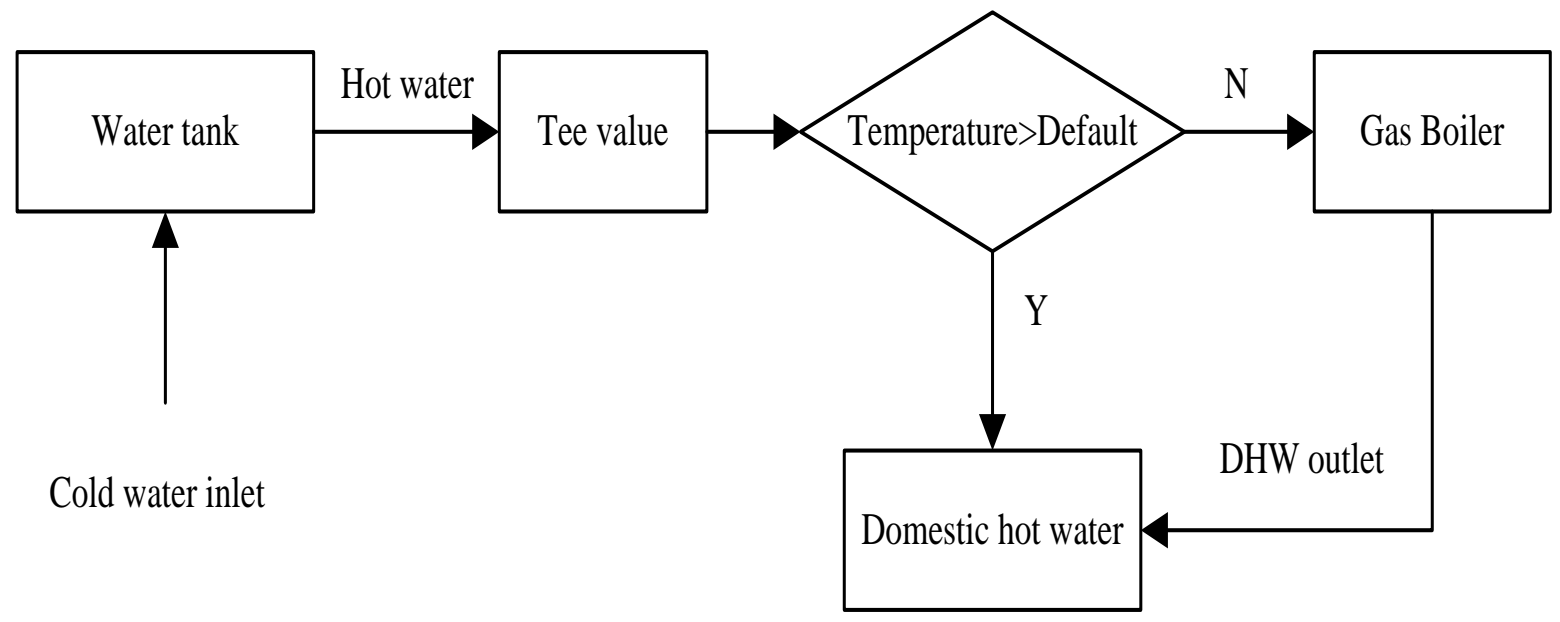

Fig -3: The flow chart of domestic hot water system

\subsubsection{Radiant Floor Heating System}

After the water was heated by the wall-mounted gas boiler and flow into the radiant floor heating system, if the temperature of outlet water (T6) is larger than the upper temperature in the storage tank (T4), it is worth recycling the heat of return water. At this time, the tee valve will be turned on in the direction of (B) and the water will flow into the exchange coil to heat the water in the storage tank. This heat recycle method can maximize the utilization of the heat. However, if T6 is less than T4, the tee valve will be turned on in the direction of (A) and the heat of return water will flow into the wall-mounted gas boiler to be heated, and then go to next cycle.

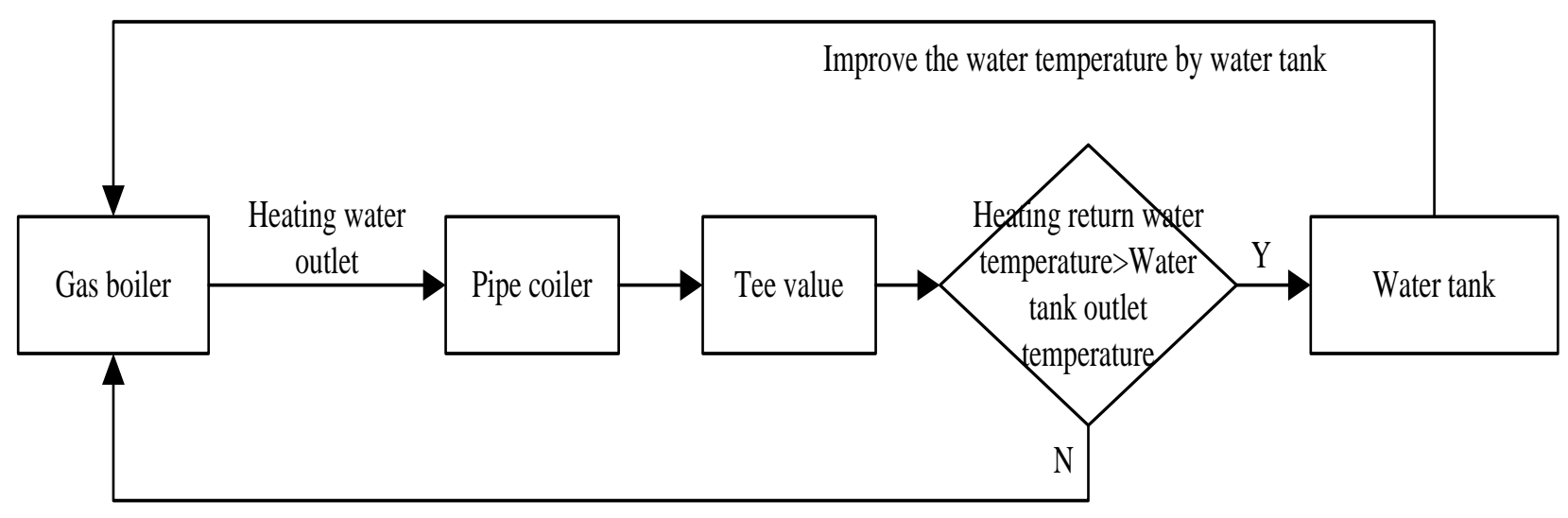

Fig -4: The flow chart of gas heating hot water system

\subsection{Design of Controlling Software}

Design of software for the slave computer is based on the S7-200 of Siemens. The corresponding programs have been completed by programming software of Siemens (STEP 7Micro/Win V4.0). There is variety of peripheral modules of S7-200 of Siemens and these modules can combine lots of controlling systems flexibility which can complete all requirements. For example, this system is combined with three EM231 RTD modules and one EM231 analog input module. It is easily to maintain these kinds of system, and these systems also have self-diagnosis function and can monitor themselves very well. The working state for the inner element of the system can be monitored by the programs that have been written. The fault location can be found easily and solved by this function coupling with the targeted programs and its self-diagnosis function. The maintenance time will be shortened and the maintenance cost of the system will be cast ${ }^{[6]}$. The structure control chart of the system is presented in figure 4 . 
The control procedure written by PLC has two control mode, which is automatic model and manual mode. When the automatic model is started, the circulation pump of solarcollector (B1) and the circulation pump (B2) of domestic hot water will be turned on and the tee valve $1 / 2$ will be turned on in the direction of $(\mathrm{B} / \mathrm{b})$ at the same moment to promote the water in this loop heating system circulate. Three minutes later, whether turn on or not the B1 pump is decided by the temperature difference between outlet temperature of solar-collector and the average temperature of the storage tank, the start-stop type of domestic hot water will be decided by the users' demands, and the direction of the tee valve is decided according to the temperature. When the manual model is started, the start-stop type of pump B1 and B2 and the direction of the tee valve are decided according to users' demands. Manual model is set to ensure users can control avoided the problem that there is something wrong with the automatic model.

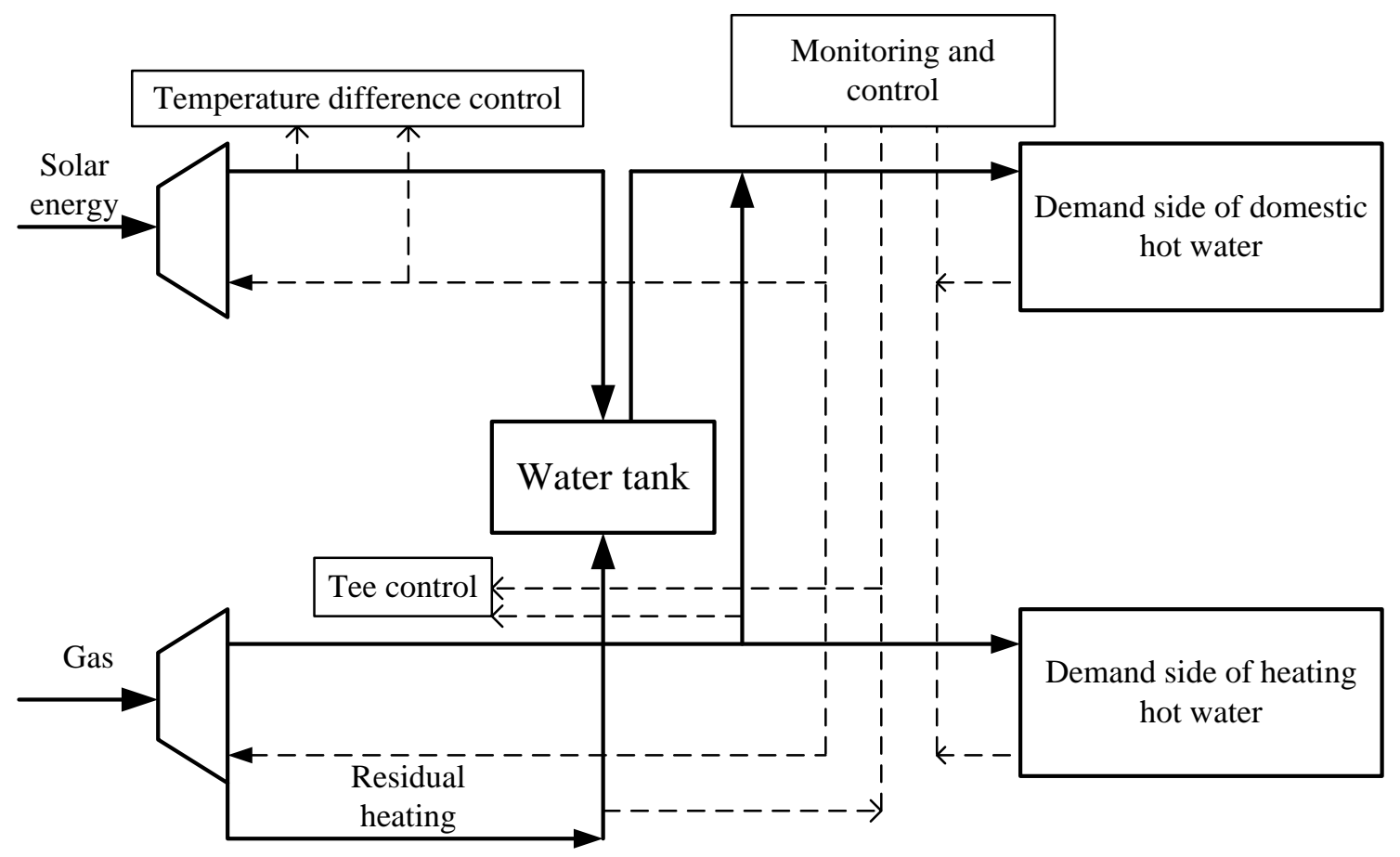

Fig -5: Schematic diagram of the structure control of system

\subsection{Design of Monitoring Software}

The host computer monitoring system adopted in this system (HMI) is developed by the configuration software (SIMATIC WinCC7.0) of Siemens, and the data archiving is completed by the normal database of Microsoft SQL Server 2000. This software also has the function of a Web browser which can realize remote monitor and adjust the real-time dynamic picture function. The software can communicate with the slave computer by OPC (OLE for Process Control). Main functions of this testing system will be described in the following chapters.

(1) The simulation of the solar energy-gas coupling system: the design of the interface for the solar energy-gas coupling system will bring the workflow more intuitive to present in front of the users. It includes circulation circuit of heating collection, circulation circuit of the radiant floor heating and circulation circuit of domestic hot water. This paper has developed dynamic results of the critical parts for coupling heating system with WinCC7.0, according to technological requirements and simulates the real-time working state of the entire system.
(2) Standardize the image design: automatic model and manual mode have been designed according to design principles and unprofessional user's demands. The interface of functional modules is very clear and the buttons is few. It can reduce the invalid operation, disoperation etc. to ensure the system operate security and stability. Monitor the key variables such as temperature and pressure on-line and alarm in time by the built-in alarming function of WinCC. The configuration software will alarm and the B1 circulation pump will be forced to turn off when the export temperature of solar-collector is larger than $95^{\circ} \mathrm{Cor}$ less than $5^{\circ} \mathrm{C}$ 
(3) The Monitor Interface is Presented As Follows

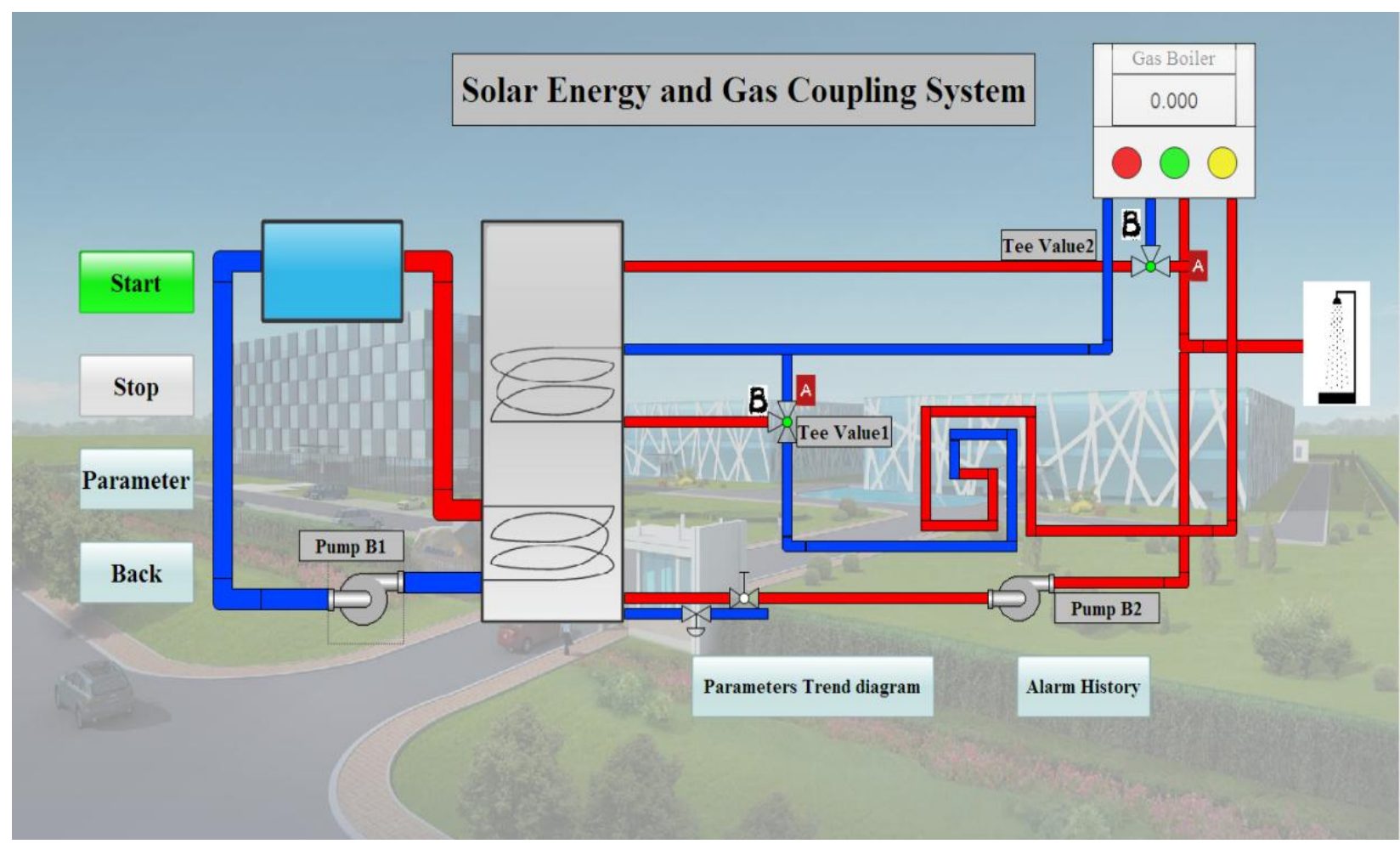

Fig -6: Monitoring interface

\subsection{Framework of the Monitoring System}

The host computer collects the real time date from PLC in this system. The monitoring system mainly includes graphical interface, parameters detection interface, process control and corresponding security mechanism. The structure diagram for the monitoring system is shown in figure 7 .

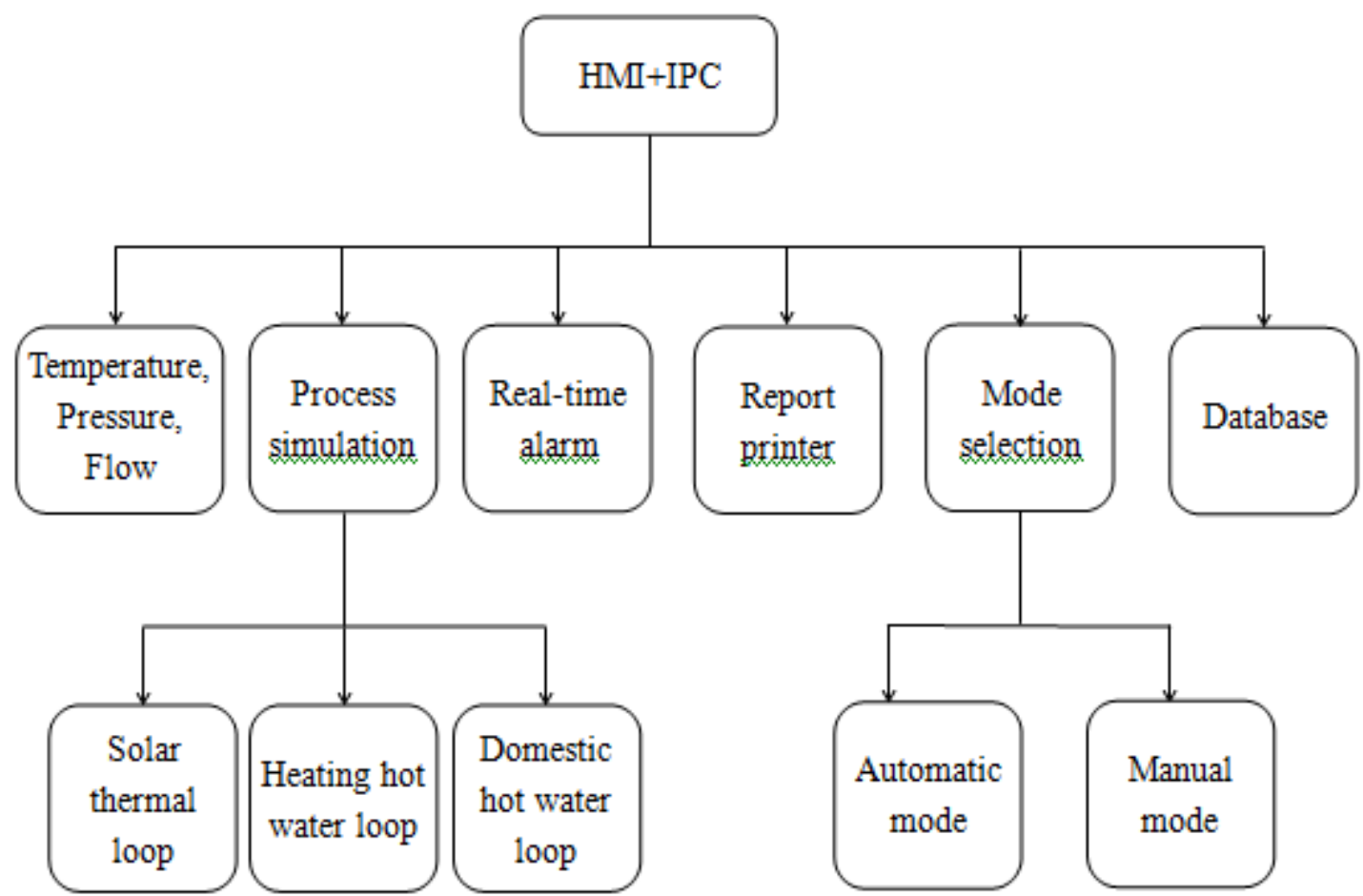

Fig -7: The structure of monitoring system 


\section{THE DESIGN OF SIGNAL SYSTEM AND COMMUNICATION SYSTEM}

Communication in this monitoring system is mainly composed of two kinds: communicate between the configuration software of WinCC and database; communicate between the configuration software of WinCC and the slave computer (PLC). However, WinCC cannot communicate with PLC directly, the communication can be achieved with OPC. Through connection the configuration software of WinCC and database, WinCC will read directly the date collected by the slave computer to the database, and it is convenient to store and access to the data.

It's necessary to build a communication between external variables and the database when WinCC communicates with the date. The external variables in this system mainly include the import and export temperature of the solarcollector, the import and export temperature of the heat medium, the import and export temperature of gas, the flow rate of the solar-collector, etc. We need to import external variables into the software of PC ACCESS to ensure both can communicate normally when WinCC communicating with PLC. And the PPI communication protocol is used between PLC and IPC, 9600 baud rate, RS232 communication mode, the local address 2 , serial port address COM2, data bit 8 , stop bit 1 , the rest is set to default setting.

\section{EXPERIMENT MEASUREMENTS}

AND

\section{ANALYSIS}

Start the software of PLC, and load the relevant program in the CPU of PLC after completing the preliminary inspection work of solar energy-gas coupling system. Then start the configuration software of WinCC, and check if or not the communication between PLC and WinCC is effect. After the communication is normal, enter the main interface of monitoring system, and select manual mode, you can test the relative part is normal or not. And you can switch to manual mode to automatic mode after all equipment can work normally. After switching to the automatic mode, the system will be in accordance with the decision rule of automatic mode to control the action of water pump and tee valve. Now excerpt partial data of gas boiler heating system for the following analysis, and the data record of gas heating loop as shown in Table 1.

Table -1: The results of gas heating loop

\begin{tabular}{|l|l|l|l|l|l|l|}
\hline Date & Time & $\begin{array}{l}\text { Supply water } \\
\text { temperature }{ }^{\circ} \mathrm{C}\end{array}$ & $\begin{array}{l}\text { Return water } \\
\text { temperature }{ }^{\circ} \mathrm{C}\end{array}$ & $\begin{array}{l}\text { Gas consumption } \\
\mathrm{m}^{3}\end{array}$ & $\begin{array}{l}\text { Cooling } \\
\text { water } \mathrm{mL}\end{array}$ & $\begin{array}{l}\text { Outside } \\
\text { temperature }{ }^{\circ} \mathrm{C}\end{array}$ \\
\hline $15-03-02$ & $9: 40: 09$ & 33.52 & 24.82 & 173 & 180 & 13.11 \\
\hline $15-03-02$ & $10: 00: 09$ & 31.23 & 25.85 & 117 & 120 & 14.21 \\
\hline $15-03-02$ & $10: 20: 09$ & 33.99 & 26.24 & 102 & 100 & 18.22 \\
\hline $15-03-02$ & $10: 40: 09$ & 40.71 & 27.88 & 96 & 100 & 19.83 \\
\hline $15-03-02$ & $11: 00: 09$ & 32.42 & 28.35 & 86 & 80 & 15.27 \\
\hline $15-03-02$ & $11: 20: 09$ & 42.77 & 27.75 & 101 & 80 & 14.39 \\
\hline
\end{tabular}

This test is the floor radiant heating test of wall-mounted gas boiler in winter, and the specific test process is shown in Fig.8.

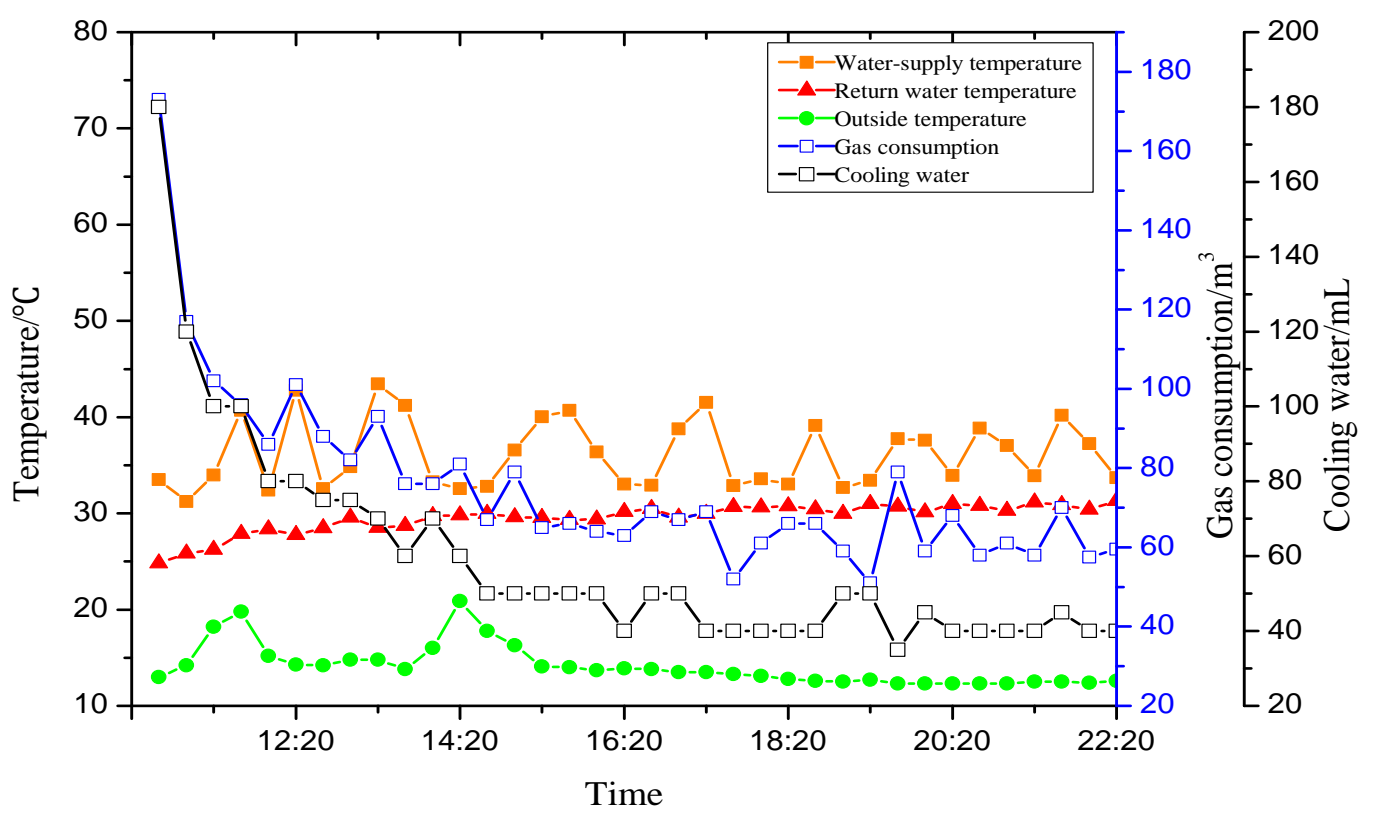

Fig -8: Process of gas heating loop 
Fig. 8 indicates that the consumption of gas and the emission of condensate are more due to the low indoor temperature at the time of the wall-mounted gas boiler has just opened. And then the consumption of gas and the emission of condensate are gradually decreasing with the gas system movement and the indoor temperature increased. Due to the intermittent operation of wall-mounted gas boiler, the supply water temperature swells and subsides while the return water temperature is stable. The detection system measured data, such as temperature, flow rate and so on has a good stability and accuracy form the above data.

\section{CONCLUSION}

Solar energy-gas coupling system can realize 24-hour nonstop running, and it can also take advantages of solar energy minimize the consumption of gas during the day on the premise of guarantee the room comfort. This will lay the foundation for establishing a scientific optimization method of solar energy-gas coupling system through constructing the solar thermal system and wall-mounted gas boiler heating system, overcome the disadvantages of the produced during the separate operation, improve the overall system efficiency, achieve energy conservation and emissions reduction. In this paper obtained the following conclusions:

(1) According to the design requirements of solar energy-gas coupling system, the related optimization design of the interface of monitoring system based on the configuration software of WinCC is carried out; users can more intuitive operation and observation the system running state.

(2) By analyzing the data from the monitoring system, the stability and accuracy of the system to collect data is verified. This will provide a solid foundation for solar energy-gas coupling system.

(3) Combined solar energy and gas has changed the traditional heating mode which is solar energy or wall-mounted gas boiler individual heating, and achieve real energy conservation and emissions reduction, which provides reliable basic data for domestic leading technology of solar energy coupling gas hot water and heating system demonstration project in Shanghai area.

\section{ACKNOWLEDGEMENTS}

This project is sponsored by Shanghai University of Engineering Science Innovation Fund for Graduate Students (No.E1-0903-14-01020)

\section{REFERENCES}

[1]. De Winter F. Energy consumption impacts of backup gas firing efficiency, tank standby losses, and pilot flame energy consumption in "two-tank"solar-gas DHW systems, subjected to the typical DHW consumption of the single family home [J]. Renewable Energy, 1996, 9 (1-4):714719.

[2]. Sun Jindong, Tong Baohua. Analysis and comparison of performance of residential water heater $[\mathrm{J}]$. Journal of Beijing Institute of Civil Engineering and Architecture, 2004, 20(2):45-49.
[3]. Chen Zhiguang, Qin Chaokui. Analysis of a hybrid water supplying system with solar collector and fuel gas [J]. Acta Energiae Solaries Sinica, 2011, 32(11):1652-1655.

[4]. Zhang Chen. Research in Baoding area of solar wall mounted gas boiler heating system [D]. Hebei University, 2014.

[5]. Mousa S Mohsen. On integrated solar water heating system $[\mathrm{J}]$. International communications in heat and mass transfer, 2002, 29(1).

[6]. Yu Junjie, Zhang Wei. PLC and HMI Applications in the Network Control[J],Control and Instruments in Chemical Industry, 2014, No.3, pp344-346.

\section{BIOGRAPHY}

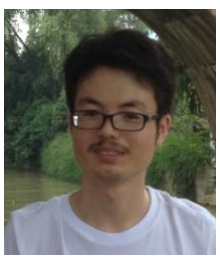

Xu Hui (1989- ), male, master of engineering, research direction for renewable energy application in buildings. E-mail: 135177974@qq.com 